\title{
Genetic structure of Gammarus fossarum populations
}

\author{
HANS REDLEF SIEGISMUND* \& JAKOB MÜLLER $\dagger$ \\ Zoological Institute, University of Munich, Seidlstraße 25, D-8000 Munich 2, Germany
}

\begin{abstract}
The population structure of Gammarus fossarum Koch was analysed at six enzyme loci in 38 populations from the Danube and Rhine drainage system in the southern part of Germany. The species-restricted distribution to the upper reaches of rivers was reflected in the large genetic differentiation of all populations. The genetic pattern can be explained as a dynamic balance between genetic drift and restricted gene flow. As migration mainly occurs along the rivers, a treelike pattern showing the genetic relationship of the populations corresponded well with the geographical position of the populations in the river system. The overall gene flow was estimated as low, although small rivers have a higher migration rate than large rivers. The watershed between the Rhine and Danube drainage basins affects gene flow at about the same level as the major migration barriers within the Danube drainage basin.

Each sampled population seemed to be panmictic with respect to the variation at single loci. In two-locus analyses, linkage disequilibria were found in several populations at combinations of three of the loci. A probable cause is that the linkage disequilibria are produced through random genetic drift (possibly through bottlenecks) and that the three loci are so closely linked that the recombination rate is too low to establish linkage equilibrium.
\end{abstract}

Keywords: gene flow, Gammarus, population structure.

\section{Introduction}

Rivers in a drainage basin are structured in a tree-like pattern, with the tributaries being the branches. Therefore, the populations of a species that live in such a system are expected to connect in a tree-like manner with restricted one-dimensional migration routes in individual rivers. A particular species may not inhabit the whole drainage system, but only favourable reaches. Thus, the local populations may be isolated by unfavourable habitats such as still waters, channels, dams and polluted rivers. The genetic structure of the population should reflect the degree of isolation among the local populations. In addition, colonization and extinction events, fluctuations of population sizes and selection gradients have an impact on the population structure.

The population structure of river-dwelling organisms has not been intensively studied. Research exists on isopods (Christensen et al., 1974), amphipods

Present addresses: *Institute of Population Biology, University of Copenhagen, Universitetsparken 15 , DK-2100 Copenhagen $\varnothing$, Denmark and $\nmid$ Zoological Institute, University of Mainz, Saarstraße 21, D-6500 Mainz, Germany.
(Gooch \& Hetrick, 1979; Bulnheim, 1985; Siegismund, 1988; Scheepmaker \& van Dalfsen, 1989; Scheepmaker, 1990) and fish (Avise \& Felley, 1979). Siegismund (1988) compared the population structures of the two amphipods Gammarus roeseli Gervais and $G$. fossarum Koch in the Isar drainage system in Bavaria. He found that the genetic divergence in populations of the two species reflected their geographical distribution pattern. G. roeseli, which is continuously distributed in the lower reaches of rivers, showed less genetic differentiation between their populations than $G$. fossarum, which has a patchy distribution in the upper reaches. Another inhabitant of the lower reaches in Southern Germany is Gammarus pulex L. The genetic structure of the populations of this species is relatively homogeneous, even on a large geographical scale (Scheepmaker \& van Dalfsen, 1989).

The patchy distribution of $G$. fossarum seems to promote the formation of subspecies. A survey of West European populations from France, Belgium, Switzerland and Germany has shown that this species is geographically differentiated in morphology as well as genetics (Scheepmaker \& van Dalfsen, 1989). This has 
caused some confusion about the correct taxonomic position of various populations. Some populations in Belgium have been described as a separate species, e.g. G. caparti (Pètre-Stroobants, 1980). Later studies have shown that these populations are conspecific with $G$. fossanum (Scheepmaker \& van Dalfsen, 1989). In addition, two groups of populations in southern France have been described as separate species closely related to G. fossarum (Scheepmaker, 1987, 1990).

The taxonomic status of many populations and the geographical boundaries of potential subspecies are still unknown. Therefore, a study of the population structure of $G$. fossarum will give a measure of the population differentiation, which serves as a potential for the formation of subspecies and new species. This study examined a restricted area of its distribution range: the Danube drainage system and a small part of the Rhine system.

\section{Materials and methods}

\section{Sampling}

Gammarus fossarum was studied in the drainage basin of the Danube in Germany. The samples were collected in the Danube, its main tributaries Inn, Isar and Lech and some smaller tributaries. Further samples were included from four brooks flowing into the Neckar, which is a tributary of the Rhine (Fig. 1). The names of the sampled rivers, the abbreviations of the localities, and the sampling dates are given in Table 1. The animals were collected by turning stones and sweeping a sieve over the sediment or by shaking plants or roots in a bucket. They were brought to the laboratory alive and identified with the keys in Karaman \& Pinkster (1977). The samples were stored in liquid nitrogen.

\section{Electrophoresis}

Whole animals were homogenized in $50 \mu$ l phosphate buffer, pH 7.4 (gel buffer for the analysis of PGM, Harris \& Hopkinson, 1976). Electrophoresis was carried out on 12 per cent starch gels with two buffer systems: a tris-maleate buffer, pH 7.2 (Harris \& Hopkinson, 1976) and an amine citrate buffer, pH 6.1 (Clayton \& Tretiak, 1972). The gels were run at $14 \mathrm{~V}$ $\mathrm{cm}^{-1}$ for $4 \mathrm{~h}$ and $20 \mathrm{~V} \mathrm{~cm}^{-1}$ for $3 \frac{3}{4} \mathrm{~h}$, respectively. The gels were stained for the enzymes mannose phosphate isomerase (MPI), E.C. No. 5.3.1.8 (Harris \& Hopkinson, 1976) and glucose phosphate isomerase (GPI), E.C. No. 5.3.1.9 (Yndgård, 1972) (the tris-maleate gels) and malate dehydrogenase (MDH), E.C. No. 1.1.1.37 (Frydenberg \& Simonsen, 1976) and glutamateoxaloacetate transaminase (GOT), E.C. No. 2.6.1.1 (Schwartz et al., 1963) (the amine-citrate gels).

Two of the enzyme stains, MDH and GOT, each revealed two stained zones, which were interpreted as the enzymes coded by two loci. The loci coding for the most anodically moving enzymes were named $M d h I$ and GotI, respectively; whereas the two loci that coded

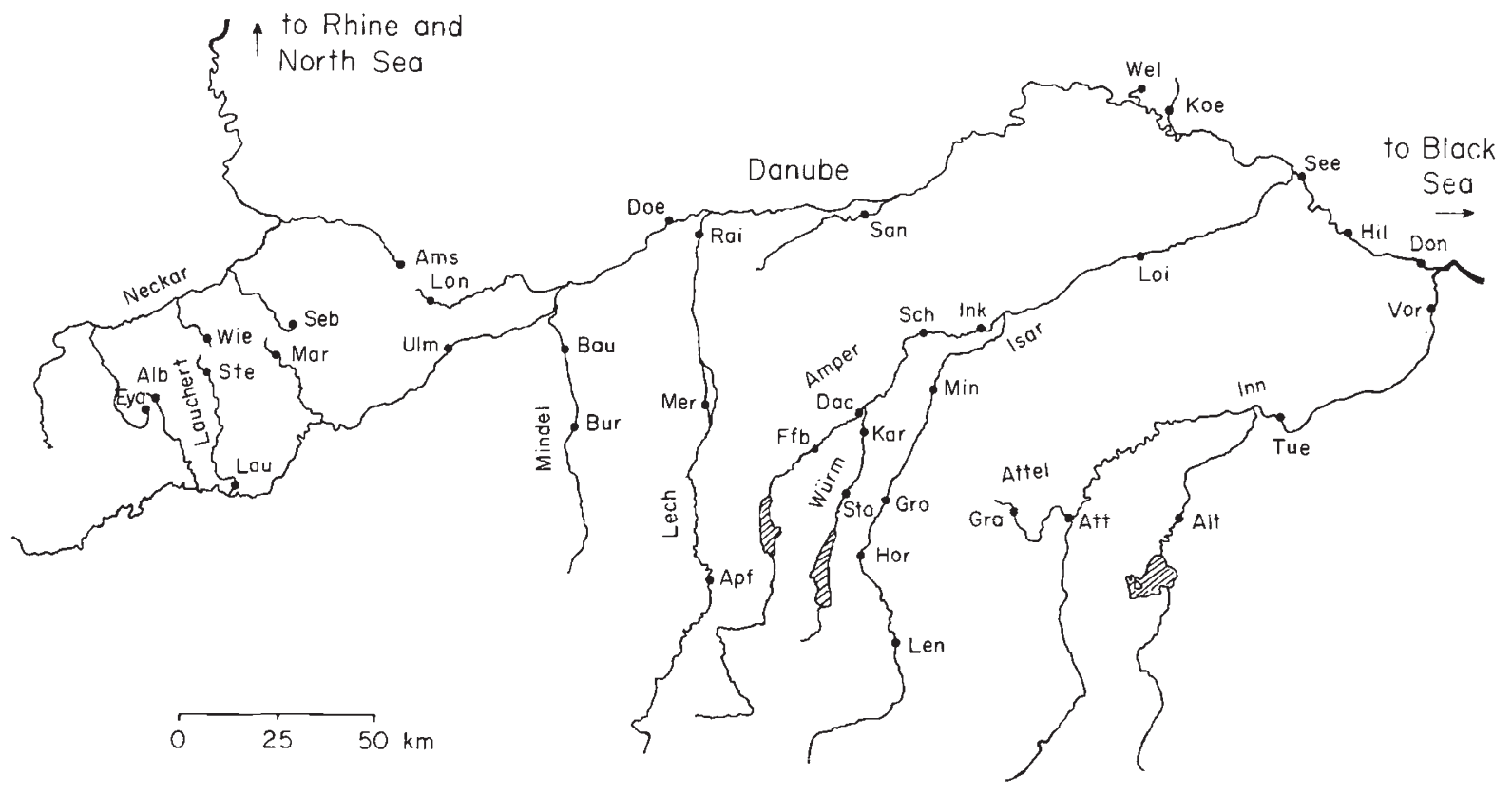

Fig. 1 Map of the sampling localities; see Table 1 for an explanation of the abbreviations. 
Table 1 Names and abbreviations of the localities, sampling dates and river names. An asterisk by the river name indicates that the sample site was in a small tributary, generally less than $500 \mathrm{~m}$ from the main river

\begin{tabular}{|c|c|c|c|}
\hline Abbreviation & Locality & Date & River \\
\hline Eya & Eyach & 4 August 1988 & Eyach \\
\hline Wie & Wiesaz & 4 August 1988 & Wiesaz \\
\hline Seb & Seeburg & 3 August 1988 & Erms \\
\hline Ams & Amstetten & 3 August 1988 & Fils \\
\hline Alb & Albstadt & 4 August 1988 & Schmiecha \\
\hline Ste & Stetten & 4 August 1988 & Lauchert \\
\hline Lau & Lauchert & 5 December 1986 & Lauchert \\
\hline Mar & Marbach & 3 August 1988 & Große Lauter \\
\hline Ulm & Ulm/Bau & 5 December 1986 & Danube* \\
\hline Bau & Burgau & 11 November 1986 & Mindel \\
\hline Bur & Burg & 11 November 1986 & Mindel \\
\hline Lon & Lonsee & 3 August 1988 & Lone \\
\hline Doe & Donauwörth & 10 November 1986 & Danube \\
\hline Rai & Rain & 10 November 1986 & Lech* \\
\hline Mer & Meringer Au/Lochbach & 4 November 1986 & Lech* \\
\hline Apf & Apfeldorf & 28 October 1986 & Lech \\
\hline San & Sandrach & 15 February 1987 & Sandrach \\
\hline Wel & Wellerbach & 7 July 1985 & Wellerbach \\
\hline Koe & Kößnach & 4 October 1985 & Kößnach \\
\hline Loi & Loiching & 31 January 1987 & Isar* \\
\hline Min & Mintraching & 28 October 1984 & Isar \\
\hline Gro & Großhesselohe & 18 April 1985 & Isar \\
\hline Hor & Hornstein & 11 December 1985 & Isar* \\
\hline Len & Lenggries & 27 September 1984 & Isar* \\
\hline Ink & Inkofen & 12 November 1984 & Amper \\
\hline Sch & Schnotting & 12 November 1984 & Amper \\
\hline Dac & Dachau & 13 October 1984 & Amper* \\
\hline $\mathrm{Ffb}$ & Fürstenfeldbruck & 6 October 1984 & Amper* \\
\hline Kar & Karlsfeld & 13 October 1984 & Würm \\
\hline Sto & Stockdorf & 13 October 1984 & Würm \\
\hline See & Seebach & 6 March 1987 & Danube* \\
\hline Hil & Hilgartsberg & 6 March 1987 & Danube* \\
\hline Don & Donauhof & 6 March 1987 & Danube* \\
\hline Vor & Vornbach & 6 March 1987 & Inn* \\
\hline Tue & Türkenbach & 5 March 1987 & Inn* \\
\hline Alt & Altenmarkt & 1 February 1987 & Alz \\
\hline Att & Attel & 5 March 1987 & Attel \\
\hline Gra & Grafing & 6 October 1984 & Attel \\
\hline
\end{tabular}

for either the cathodically or less anodically moving enzymes were named MdhII and GotII, respectively. The mobility of the most common electromorph was set to 100 ; the mobility of the other electromorphs were measured relatively to this electromorph. Most electromorphs at the GotII and MdhII loci moved cathodically. Anodically moving electromorphs at these loci are indicated with a minus (Table 2).

\section{Statistics}

The observed genotypic proportions were compared to Hardy-Weinberg expectations. As many samples had more than two alleles at polymorphic loci, the test was carried out by pooling all rare alleles with the second most common allele. Deviations from Hardy-Weinberg proportions were tested with the 
Table 2 Relative mobilities of the alleles. Collective alleles are indicated with the span of their relative mobilities

\begin{tabular}{lllllllllll}
\hline & Allele & \multicolumn{10}{l}{ L } & \multicolumn{1}{l}{ Locus } & 1 & 2 & 3 & 4 & 5 & 6 & 7 & 8 & 9 \\
\hline Gpi & 123 & 113 & 108 & 100 & 92 & 76 & 68 & 62 & 57 \\
Mpi & 111 & 107 & 100 & 93 & 86 & 78 & & & \\
GotI & 107 & 100 & 90 & $85-76$ & 69 & & & & \\
GotII & $150-137$ & 100 & $62-20$ & & & & & & \\
MdhI & 107 & 100 & 85 & $75-67$ & & & & & \\
MdhII & $450-300$ & 100 & -77 & $-157--367$ & & & & & \\
\hline
\end{tabular}

statistic $F \sqrt{N}$, where $F$ is Wright's fixation index and $N$ is the sample size (Brown, 1970). Negative values indicate an excess of heterozygotes, positive values an excess of homozygotes. The test statistic is approximately normal distributed with zero mean and unit variance; values outside the range -1.96 to 1.96 indicate significant deviations from Hardy-Weinberg proportions at the 5 per cent level. Test values were only calculated when the frequency of the most common allele was less than 0.95 .

The linkage disequilibrium parameter $(D)$ was estimated according to the methods of Hill (1974) and Weir \& Cockerham (1979). As in the test for Hardy-Weinberg proportions, rare alleles were pooled so that $D$ was estimated for a two-locus two-allele polymorphism where the second allele is a collective allele, thus the polymorphism consists of four gametes and nine possible genotypes. The test was only carried out when the frequency of the most common allele in both loci was less than 0.95 .

If there is a random union of gametes the frequencies of the four gametes can be estimated with the gene counting procedure in Hill (1974). The gamete frequencies are used to calculate the expected frequencies of the nine genotypes. A comparison of observed and expected genotype numbers can therefore be used to test a hypothesis of random union of gametes. This hypothesis is tested with a likelihood ratio test with degrees of freedom equal to the difference in the number of parameters needed to describe the data. The observed genotypes are described by $8(=9-1)$ parameters and the gamete frequencies with $3(=4-1)$ parameters. Therefore, the degrees of freedom are five.

The hypothesis of no linkage disequilibrium $(D=0)$ can only be tested with Hill's method when the hypothesis of random union of gametes has been accepted. This hypothesis has 1 d.f. because only two parameters (the allele frequencies at the two loci) are needed to describe the data instead of the three parameters for the gamete frequencies. With non-random union of gametes, Hill's method cannot be used. Instead, Burrow's estimator $\Delta$ is found and $\Delta=0$ is tested with a chi-square test with 1 d.f. (Weir \& Cockerham, 1979).

The population structure of $G$. fossarum is summarized by estimating $F$-statistics (Wright, 1951). Estimators of $F_{\text {IT }}, F_{\text {IS }}$ and $F_{\text {ST }}$ were found for each locus separately and as a combined estimate over all loci with the procedures described by Weir \& Cockerham (1984). The standard deviations of the estimators $F_{\mathrm{IT}}, F_{\mathrm{IS}}$ and $F_{\mathrm{ST}}$ were found with the jackknife procedure by excluding each sample in turn (Weir \& Cockerham, 1984). We use the conventional notation $F_{\mathrm{ST}}$ instead of Weir \& Cockerham's parameter $\theta$.

The overall gene flow was estimated from the $F_{\mathrm{ST}^{-}}$ statistic. In the island model, the level of population differentiation is determined by the gene flow, which is measured by the average number of migrants exchanged between local populations per generation $(\mathrm{Nm})$ where $N$ is the average effective population size and $m$ is the average migration rate (Wright, 1951). At the equilibrium, $\mathrm{Nm}$ can be found from the relation

$F_{\mathrm{ST}}=\frac{1}{1+4 N m}$.

Slatkin (1985) used another method to calculate the gene flow directly from the average frequency of private alleles, $\dot{p}(1)$. This method was dropped because it needs at least 20 private alleles in the data set. There was only one private allele in our dataset, Ams $G p i^{9}$. In addition, Slatkin \& Barton (1989) have shown that this method yields comparable results to the $F_{\mathrm{ST}}$ method.

The genetic relationships between the populations were estimated by the restricted maximum likelihood method with the program CONTML from the package Phylip, version 3.3 (Felsenstein, 1985). The input of the program is the allele frequencies at all loci. The phylogenetic relationships among the populations were estimated under the assumption that the lineages split 
and evolve independently by random genetic drift (Felsenstein, 1981). Felsenstein recommends that the program is run at least 10 times with the input order of the species shuffled randomly. We have run the program 30 times with the 'global' option. Ten times would have been sufficient because a phylogenetic tree with the maximum likelihood was found among the first 10 runs of the program (as well as the next two groups of 10 runs). The program conTML allows trees with different topologies to be compared with each other. This is done by estimating the standard deviations of the log likelihoods for the trees. A tree with a

Table 3 Tests for Hardy-Weinberg proportions. $N$ is the sample size, $F \sqrt{N}$ is the test statistic

\begin{tabular}{|c|c|c|c|c|c|c|c|c|c|c|c|c|}
\hline \multirow[b]{2}{*}{ Station } & \multicolumn{2}{|l|}{ Gpi } & \multicolumn{2}{|l|}{$M p i$} & \multicolumn{2}{|l|}{ GotI } & \multicolumn{2}{|c|}{ GotII } & \multicolumn{2}{|c|}{$M d h I$} & \multicolumn{2}{|c|}{$M d h I I$} \\
\hline & $N$ & $F \sqrt{N}$ & $N$ & $F \sqrt{N}$ & $N$ & $F \sqrt{N}$ & $N$ & $F \sqrt{N}$ & $N$ & $F \sqrt{N}$ & $N$ & $F \sqrt{N}$ \\
\hline Еya & 90 & 0.14 & 86 & 3.21 & 90 & -1.05 & 90 & 0.38 & 89 & -0.56 & 85 & \\
\hline Wie & 0 & & 88 & -0.51 & 90 & -0.50 & 90 & & 88 & & 87 & 0.48 \\
\hline Seb & 90 & & 89 & -1.15 & 88 & -0.94 & 90 & & 89 & -1.03 & 89 & \\
\hline Ams & 90 & 0.17 & 88 & -0.17 & 87 & 0.76 & 89 & -0.35 & 87 & -0.51 & 89 & \\
\hline Alb & 90 & -1.27 & 88 & 1.09 & 89 & 1.78 & 89 & 1.23 & 89 & & 89 & \\
\hline Ste & 90 & & 88 & 0.20 & 90 & -0.14 & 90 & & 89 & & 86 & \\
\hline Lau & 118 & 0.08 & 114 & -0.36 & 111 & -0.22 & 119 & & 117 & & 113 & \\
\hline Mar & 90 & -0.56 & 86 & -0.74 & 90 & 0.54 & 90 & & 89 & 1.71 & 87 & 1.22 \\
\hline Ulm & 119 & -0.29 & 96 & 1.78 & 112 & 0.64 & 114 & & 60 & 0.48 & 96 & \\
\hline Bur & 118 & -1.04 & 119 & -0.57 & 117 & -0.57 & 119 & & 114 & & 103 & \\
\hline Bau & 118 & 1.03 & 116 & 0.50 & 117 & 1.03 & 118 & & 116 & & 106 & \\
\hline Lon & 90 & 0.09 & 88 & 0.11 & 88 & -0.42 & 90 & & 90 & & 89 & \\
\hline Doe & 97 & -1.17 & 86 & 0.43 & 60 & -1.07 & 85 & 1.38 & 109 & 1.59 & 93 & \\
\hline Apf & 120 & 1.51 & 123 & & 124 & & 124 & & 124 & & 124 & \\
\hline Mer & 119 & 1.25 & 110 & & 117 & 0.43 & 114 & & 115 & & 103 & \\
\hline Rai & 120 & 0.52 & 120 & 0.48 & 118 & 0.11 & 119 & & 120 & 0.81 & 120 & \\
\hline San & 118 & -1.19 & 116 & -0.93 & 118 & 2.02 & 118 & 1.63 & 119 & -1.10 & 120 & \\
\hline Mue & 64 & & 64 & & 64 & & 64 & & 63 & & 60 & \\
\hline Koe & 70 & 2.11 & 72 & -1.75 & 63 & -1.66 & 72 & 1.33 & 69 & & 69 & \\
\hline $\mathrm{Ffb}$ & 48 & -1.52 & 48 & 1.38 & 48 & -0.25 & 48 & & 18 & 0.67 & 18 & \\
\hline Dac & 90 & -2.14 & 85 & & 88 & -0.51 & 90 & & 90 & & 87 & \\
\hline Sch & 72 & 0.85 & 72 & -1.29 & 72 & -0.54 & 72 & & 71 & -0.27 & 68 & \\
\hline Ink & 44 & -0.05 & 44 & 2.56 & 44 & -0.13 & 44 & & 44 & 1.82 & 44 & \\
\hline Sto & 87 & -0.90 & 85 & & 83 & -0.57 & 86 & & 84 & & 64 & \\
\hline Kar & 118 & 0.79 & 118 & & 118 & 0.15 & 118 & & 118 & & 118 & \\
\hline Len & 96 & & 96 & & 97 & & 97 & & 74 & & 73 & \\
\hline Hor & 110 & & 107 & 0.28 & 110 & & 119 & & 109 & & 82 & \\
\hline Gro & 110 & -0.71 & 110 & -1.05 & 111 & & 111 & & 110 & & 98 & \\
\hline Min & 27 & & 27 & 0.08 & 25 & -0.43 & 27 & & 27 & -0.90 & 27 & \\
\hline Loi & 119 & & 77 & 0.07 & 100 & -1.82 & 119 & -1.17 & 118 & & 119 & \\
\hline See & 54 & 0.08 & 52 & -0.44 & 48 & -0.94 & 56 & & 55 & 2.17 & 54 & \\
\hline Hil & 119 & 0.67 & 95 & 2.26 & 106 & -1.22 & 117 & 0.62 & 106 & 0.89 & 105 & \\
\hline Don & 115 & -0.45 & 75 & 1.44 & 101 & 0.65 & 137 & 0.37 & 131 & -1.09 & 111 & \\
\hline Gra & 131 & -0.91 & 133 & & 133 & & 133 & & 118 & & 113 & \\
\hline Att & 72 & 0.06 & 71 & & 72 & 1.75 & 72 & & 72 & & 72 & \\
\hline Alt & 119 & & 119 & & 120 & & 120 & & 120 & & 120 & \\
\hline Tue & 47 & & 47 & & 47 & -0.47 & 45 & & 47 & & 47 & \\
\hline Vor & 18 & & 18 & & 18 & & 18 & & 18 & & 18 & \\
\hline Mean & & -0.106 & & 0.266 & & -0.107 & & 0.602 & & 0.312 & & 0.850 \\
\hline Var & & 1.012 & & 1.551 & & 0.945 & & 0.842 & & 1.361 & & 0.274 \\
\hline $\mathrm{N}$ & & 27 & & 26 & & 29 & & 9 & & 15 & & 2 \\
\hline $\mathrm{P}($ normal $)$ & & 0.973 & & 0.509 & & 0.329 & & 0.341 & & 0.123 & & 1 \\
\hline $\mathrm{P}($ mean $=0)$ & & 0.295 & & 0.857 & & 0.280 & & 0.958 & & 0.841 & & 0.869 \\
\hline $\mathrm{P}(\operatorname{var}=1)$ & & 0.554 & & 0.961 & & 0.453 & & 0.435 & & 0.837 & & 0.399 \\
\hline
\end{tabular}


log likelihood that differs more than 1.96 times its standard deviation from the tree with the maximum likelihood is considered significantly different at the 5 per cent level.

\section{Results}

\section{Genotypic variation at single loci}

In a preliminary study a total of eight enzyme stains were used that were known to be polymorphic in other Gammarus species (Siegismund et al., 1985). Three enzyme stains were difficult to score and one was monomorphic. Therefore, the four enzyme stains used in this study reveal the variation at a group of six selected loci that show a higher degree of heterozygosity than a random sample of loci would do.

The six studied loci differed considerably in the level of variation, spanning from three alleles at the GotII locus to nine alleles at the Gpi locus (Table 2). The average observed heterozygosity was 0.17 with the highest contribution from the Gpi locus (0.33) followed by the other five loci in the order GotI (0.29), Mpi (0.24), $M d h I(0.10)$, GotII (0.07) and $M d h I I(0.02)$.

The genotypic distributions at the six loci accord with Hardy-Weinberg expectations (Table 3). There is no suggestion of either heterozygote deficiency nor excess at any of the loci. The test statistics $F \sqrt{N}$ are normally distributed; see line $\mathrm{P}$ (normal) which is the Shapiro-Wilk statistic for the test that the data are sampled from a normal distribution (SAS, 1987), the means and the variances of the distributions do not differ from the expected 0 and 1 , respectively. Line $\mathrm{P}($ mean $=0)$ is the cumulative probability of observing a $t$-value in the test for mean $=0$ based on the observed distribution. Line $P(\operatorname{Var}=1)$ is the cumulative probability for observing the test statistic. [The test statistic is computed as $(N-1)$ Var and is approximately chisquare distributed with $N-1$ degrees of freedom, Sokal \& Rohlf (1981).. The variation at single loci can therefore be described by the allele frequencies and the notion that the genotypic proportions accord with Hardy-Weinberg expectations.

\section{Genotypic variation at two locus combinations}

Hardy-Weinberg proportions are attained after a single generation with random mating in a large population without selection. If, for some reason, a linkage disequilibrium has arisen in a population, it decays with a rate proportional to the recombination fraction among the studied loci. In $G$. fossarum, the marginal one-locus combinations do not differ from the expected Hardy-Weinberg distributions. In this section we study the genotypic distributions of the 15 two-locus combinations at the six loci. Alleles were pooled as for the one-locus tests. The following strategy was adopted: the allele that was the most common over all populations was chosen as allele 1 and the other alleles were pooled as allele 2. The reason for this procedure was that it is then possible to use the signs of the estimates of the linkage disequilibrium parameter $(D)$ in addition to the test statistics. For a particular combination of loci the signs of $D$ are expected to show a $1: 1$ distribution of positive and negative values across the populations when there are no systematic trends that influence this parameter. None of the 15 pairs of loci showed such a deviation from the expected one.

The tests for the hypothesis of linkage equilibrium are given in Tables 4 and 5. They consist of two sequential tests. First, the hypothesis of random union of gametes is tested. If this hypothesis is accepted, an estimate of $D$ is found with the procedure of Hill (1974) and the second hypothesis, $D=0$, is tested with a likelihood ratio test. If the hypothesis of random union is rejected at the 5 per cent level, the hypothesis of $D=0$ is tested by using Burrow's estimator $\Delta$ for $D$. In the tests for random union of gametes there were several cases with low expectations in the genotypic arrays. The two-locus combinations with low expectations were not pooled, but there was no suggestion of any effect of low expectations on the outcome of the tests. The sums of the test statistics are given in Table 6 , where the test of the combinations of the loci that included $M d h I I$ are also given.

The hypotheses of random union of gametes is accepted for almost all combinations of the loci in pairs. The sum of test statistics for the combinations Mpi/MdhI and GotI/GotII are significant at the 5 per cent level. These two significances are absorbed in the total sum. We accept, therefore, the hypothesis of a random union of gametes. This result is not surprising considering that the marginal one-locus distributions accord with Hardy-Weinberg expectations.

The hypothesis of no linkage disequilibrium is rejected in several cases at the 5 per cent level. The significant cases are randomly distributed over the populations. There are no suggestions that they occur more frequently in certain parts of the river system or that they occur between several loci in the same population. The latter might have been expected if a population were a mixture of immigrants from several genetically different populations. The significant deviations from linkage equilibrium are not random combinations of the six loci. They mostly involve combinations of the loci Mpi, GotI and GotII. The strongest indication of linkage disequilibrium is found 
Table 4 Test statistics for the hypotheses of random union of gametes (RUG) and linkage equilibrium(LE). Tests that are significant at the 5 per cent level are indicated with an asterisk

\begin{tabular}{|c|c|c|c|c|c|c|c|c|c|c|}
\hline \multirow[b]{2}{*}{ Station } & \multicolumn{2}{|c|}{ Gpi/Mpi } & \multicolumn{2}{|c|}{ Gpi/GotI } & \multicolumn{2}{|c|}{ Gpi/GotII } & \multicolumn{2}{|c|}{ Gpi/MdhI } & \multicolumn{2}{|c|}{ Mpi/GotI } \\
\hline & RUG & LE & RUG & LE & RUG & $\mathrm{LE}$ & RUG & LE & RUG & LE \\
\hline Eya & 10.78 & 0.11 & 3.29 & 0.08 & 6.25 & 0.46 & 4.96 & 0.28 & $13.61^{*}$ & 1.06 \\
\hline Wie & & & & & & & & & 2.06 & 0.97 \\
\hline Seb & & & & & & & & & 4.16 & 0.14 \\
\hline Ams & 4.56 & 1.93 & 2.00 & 2.81 & 2.08 & 0.14 & 2.61 & 0.96 & 3.13 & 0.29 \\
\hline Alb & 3.42 & 1.74 & 11.07 & 0.33 & 4.23 & 0.06 & & & 5.42 & $4.00^{*}$ \\
\hline Ste & & & & & & & & & 1.26 & $6.01 *$ \\
\hline Lau & 0.77 & 2.59 & 2.21 & 0.35 & & & & & 2.26 & 1.36 \\
\hline Mar & 1.32 & 3.66 & 1.82 & 0.01 & & & 2.62 & 0.00 & 1.50 & 0.90 \\
\hline Ulm & 9.23 & 1.09 & 2.57 & 0.99 & & & 2.72 & 1.72 & 2.34 & $4.03^{*}$ \\
\hline Bur & 2.54 & 0.07 & 9.23 & 0.11 & & & & & 2.59 & $4.27^{*}$ \\
\hline Bau & 7.77 & 0.01 & 6.95 & 2.34 & & & & & 6.33 & 0.00 \\
\hline Lon & 1.13 & 0.54 & 6.64 & 0.21 & & & & & 4.24 & 0.17 \\
\hline Doe & 5.53 & 0.38 & 9.21 & 0.14 & 4.01 & 1.84 & 7.42 & 0.98 & 2.87 & 0.75 \\
\hline \multicolumn{11}{|l|}{ Apf } \\
\hline Mer & & & 9.13 & 0.00 & & & & & & \\
\hline Rai & 6.74 & 3.04 & 1.02 & 0.00 & & & 9.21 & 0.05 & 4.43 & 1.63 \\
\hline San & 9.60 & 0.54 & 8.58 & 1.02 & 10.16 & 0.87 & 6.09 & 1.09 & 7.31 & 2.70 \\
\hline \multicolumn{11}{|l|}{ Mue } \\
\hline Koe & $13.10^{*}$ & 0.87 & 6.64 & 0.07 & 9.87 & $5.82^{*}$ & & & $12.53^{*}$ & 1.06 \\
\hline $\mathrm{Ffb}$ & 5.89 & 0.12 & 8.73 & 0.17 & & & 1.74 & 0.04 & 1.91 & 2.81 \\
\hline $\mathrm{Dac}$ & & & 1.57 & 0.13 & & & & & & \\
\hline Sch & 4.47 & $4.71^{*}$ & 2.19 & 0.92 & & & 3.57 & 1.03 & 3.26 & 1.96 \\
\hline Ink & 7.86 & $5.52^{*}$ & 4.97 & 2.88 & & & 8.09 & 0.17 & 7.14 & 0.16 \\
\hline Sto & & & 3.98 & 1.46 & & & & & & \\
\hline Kar & & & 8.71 & 2.55 & & & & & & \\
\hline \multicolumn{11}{|l|}{ Len } \\
\hline \multicolumn{11}{|l|}{ Hor } \\
\hline \multicolumn{11}{|l|}{ Gro } \\
\hline Min & & & & & & & & & 8.62 & $6.93^{*}$ \\
\hline Loi & & & & & & & & & 3.77 & 0.00 \\
\hline See & 10.32 & 0.00 & 3.67 & 0.16 & & & 4.23 & 1.99 & 2.87 & $8.80^{*}$ \\
\hline Hil & 6.36 & 0.32 & 3.11 & 0.40 & 1.39 & 0.09 & 2.98 & 1.05 & $12.29^{*}$ & 0.11 \\
\hline Don & 3.06 & 1.06 & 2.82 & 1.99 & 5.59 & 2.33 & 1.80 & 0.28 & 5.42 & 1.35 \\
\hline \multicolumn{11}{|l|}{ Gra } \\
\hline Att & & & 2.66 & 0.66 & & & & & & \\
\hline \multicolumn{11}{|l|}{ Alt } \\
\hline Tue & & & & & & & & & & \\
\hline Vor & & & & & & & & & & \\
\hline
\end{tabular}

for the Mpi/GotI combination, six out of 24 tests are significant at the 5 per cent level. The sum of the test statistics is significant at the 0.1 per cent level. The evidence at the two other pairs, Mpi/GotI and GotI/ GotII, is somewhat weaker, but in both cases the sum of the test statistics is significant at the 5 per cent level. The three significant cases are not absorbed in the total sum of the test statistics, which is significant at the 0.5 per cent level (Table 6). Thus, we conclude that there are several populations of $G$ fossarum that are not in gametic phase equilibrium. Possible reasons for this are discussed below.

\section{Population structure}

Despite the suggestion that there is linkage disequilibrium between some of the studied loci in $G$. fossarum (in particular the combination Mpi and GotI) 
Table 5 Test statistics for the hypotheses of random union of gametes (RUG) and linkage equilibrium (LE). Tests that are significant at the 5 per cent level are indicated with an asterisk

\begin{tabular}{|c|c|c|c|c|c|c|c|c|c|c|}
\hline \multirow[b]{2}{*}{ Station } & \multicolumn{2}{|c|}{ Mpi/GotII } & \multicolumn{2}{|c|}{ Mpi/MdhI } & \multicolumn{2}{|c|}{ GotI/GotII } & \multicolumn{2}{|c|}{ GotI/MdhI } & \multicolumn{2}{|c|}{ GotII/MdhI } \\
\hline & RUG & LE & RUG & $\mathrm{LE}$ & RUG & LE & RUG & LE & RUG & LE \\
\hline $\begin{array}{l}\text { Eya } \\
\text { Wie }\end{array}$ & $13.05^{*}$ & $5.47^{*}$ & 9.53 & 0.03 & 2.95 & 0.30 & 2.40 & 0.68 & 1.57 & 1.23 \\
\hline Seb & & & 7.65 & 0.68 & & & 2.70 & 0.61 & & \\
\hline Ams & 3.72 & 0.09 & 7.21 & 2.16 & 5.29 & $5.09 *$ & & & 0.78 & 0.03 \\
\hline $\begin{array}{l}\text { Alb } \\
\text { Ste } \\
\text { Lau }\end{array}$ & 3.65 & 2.12 & & & $11.44^{*}$ & 0.05 & & & & \\
\hline Mar & & & & & & & 3.87 & 0.09 & & \\
\hline $\begin{array}{l}\text { Ulm } \\
\text { Bur } \\
\text { Bau }\end{array}$ & & & 3.48 & 0.49 & & & 8.14 & 1.09 & & \\
\hline Lon & & & & & & & & & & \\
\hline $\begin{array}{l}\text { Doe } \\
\text { Apf } \\
\text { Mer }\end{array}$ & 1.54 & 0.01 & 4.57 & 0.56 & 1.67 & 3.49 & 2.67 & 0.24 & 2.62 & 0.55 \\
\hline Rai & & & 5.62 & 0.39 & & & 4.91 & 0.03 & & \\
\hline $\begin{array}{l}\text { San } \\
\text { Mue }\end{array}$ & 6.29 & 3.36 & 4.69 & 0.11 & 9.09 & 0.09 & 7.84 & 0.02 & & \\
\hline Koe & 7.68 & 0.01 & & & $12.44^{*}$ & 1.01 & & & & \\
\hline $\begin{array}{l}\text { Ffb } \\
\text { Dac }\end{array}$ & & & 4.84 & 0.32 & & & 3.35 & 0.61 & & \\
\hline Sch & & & 6.77 & 0.97 & & & 0.91 & $4.52^{*}$ & & \\
\hline Ink & & & 9.67 & 1.89 & & & 7.13 & 0.54 & & \\
\hline Sto & & & & & & & & & & \\
\hline Kar & & & & & & & & & & \\
\hline Len & & & & & & & & & & \\
\hline Hor & & & & & & & & & & \\
\hline Gro & & & & & & & & & & \\
\hline Min & & & & & & & 3.86 & 1.46 & & \\
\hline Loi & & & & & 6.12 & 1.74 & & & & \\
\hline See & & & 11.06 & 2.17 & & & 8.69 & $5.50^{*}$ & & \\
\hline Hil & 5.90 & $5.30^{*}$ & 6.47 & 0.02 & 7.27 & 1.40 & 7.55 & 0.29 & 5.48 & 0.51 \\
\hline Don & 7.72 & 0.12 & 5.79 & 1.12 & 11.03 & $4.10^{*}$ & 2.93 & 0.88 & & \\
\hline Gra & & & & & & & & & & \\
\hline Att & & & & & & & & & & \\
\hline Alt & & & & & & & & & & \\
\hline Tue & & & & & & & & & & \\
\hline Vor & & & & & & & & & & \\
\hline
\end{tabular}

we begin by describing the population structure by single locus gene frequencies. The gene frequencies at the six polymorphic loci are depicted in Figs 2-7. Less common alleles are pooled.

The first impression of the geographical differentiation in $G$. fossarum is that most of the samples differ from each other in the gene frequencies in at least one locus. There are very few pairs of populations that do not differ in allele frequency from each other. Len and Wel are both almost fixed for the same alleles but are separated from each other along rivers where the populations have very different gene frequencies. The other example of a pair of populations that are almost fixed for the same alleles is Vor and Alt from the Inn 
Table 6 Sum of the test statistics for the hypotheses of random union of gametes (RUG) and linkage equilibrium (LE)

\begin{tabular}{|c|c|c|c|c|c|c|}
\hline \multirow{2}{*}{$\begin{array}{l}\text { Combination } \\
\text { of loci }\end{array}$} & \multicolumn{3}{|l|}{ RUG } & \multicolumn{3}{|l|}{$\mathrm{LE}$} \\
\hline & $\chi^{2}$ & d.f. & $P$ & $\chi^{2}$ & d.f. & $P$ \\
\hline Gpi/Mpi & 114.43 & 95 & 0.085 & 28.29 & 19 & 0.078 \\
\hline Gpi/GotI & 122.77 & 120 & 0.413 & 19.76 & 24 & 0.710 \\
\hline Gpi/GotII & 43.59 & 40 & 0.322 & 11.61 & 8 & 0.169 \\
\hline Gpi/MdhI & 58.04 & 65 & 0.717 & 9.64 & 13 & 0.723 \\
\hline Gpi/MdhII & 2.14 & 5 & 0.830 & 0.99 & 1 & 0.319 \\
\hline Mpi/GotI & 121.30 & 120 & 0.450 & 51.45 & 24 & 0.001 \\
\hline Mpi/GotII & 49.56 & 40 & 0.143 & 16.48 & 8 & 0.036 \\
\hline$M p i / M d h I$ & 87.33 & 65 & 0.034 & 10.91 & 13 & 0.619 \\
\hline Mpi/MdhII & 2.95 & 5 & 0.708 & 0.37 & 1 & 0.544 \\
\hline GotI/GotII & 67.29 & 45 & 0.017 & 17.27 & 9 & 0.046 \\
\hline GotI/MdhI & 66.96 & 70 & 0.581 & 16.58 & 14 & 0.279 \\
\hline GotI/MdhII & 6.37 & 5 & 0.272 & 0.01 & 1 & 0.906 \\
\hline GotII/MdhI & 15.38 & 25 & 0.932 & 4.50 & 5 & 0.479 \\
\hline GotII/MdhII & & & & & & \\
\hline$M d h I / M d h I I$ & 5.48 & 5 & 0.360 & 0.00 & 1 & 1 \\
\hline Sum & 763.59 & 705 & 0.062 & 187.86 & 141 & 0.005 \\
\hline
\end{tabular}

drainage system. Both samples differ from Tue, which is found in between. Vor and Alt must therefore be considered as different populations.

It is possible to partition the populations into groups that are relatively homogeneous. We do this in a qualitative way here.
Group 1: Gra, Att, Alt, Tue, Vor belong to the Inn system. It can be distinguished from all other groups by the high frequency of allele 3 at the Gpi locus.

Group 2: this group comprises the Isar populations that were studied by Siegismund (1988) plus the Loi population. Except for the Dac and especially the Len population, this group has a relatively high frequency of allele $G p i^{4}$.

Group 3: See, Hil and Don have a relatively high frequency of the alleles $G p i^{2}$ and $M d h I^{1}$.

Group 4: is small, it consists of Wel and Koe. They are characterized by a high frequency of $G p i^{2}$.

The remaining populations are more heterogeneous, which makes it difficult to group them but we have chosen to partition them into two groups,

Group 5: the remaining populations in the Danube drainage system with a relatively high frequency of allele $G p i^{6}$.

Group 6: comprises the four populations from brooks that are connected to the Rhine drainage system.

The distribution range of a population is less than the distances between the sampling stations (measured along the river beds the average distance is about 40 $\mathrm{km})$. This can be seen from Table 7, where the gene frequencies are compared among the 10 pairs of neighbouring populations with the lowest genetic distances, which are calculated according to Nei (1972). The allele frequencies are compared by likelihood ratio

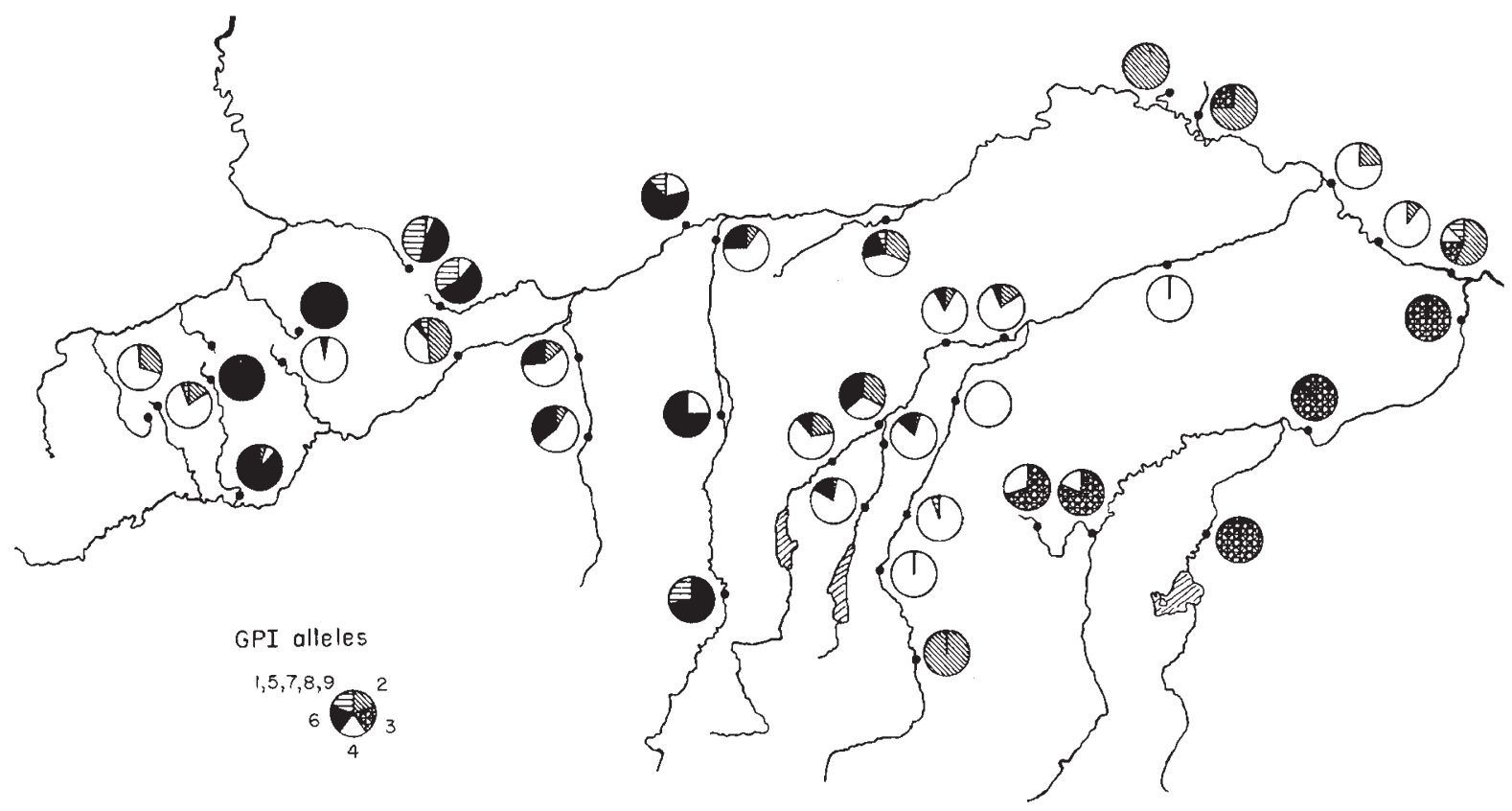

Fig. 2 Allele frequencies at the Gpi locus. 


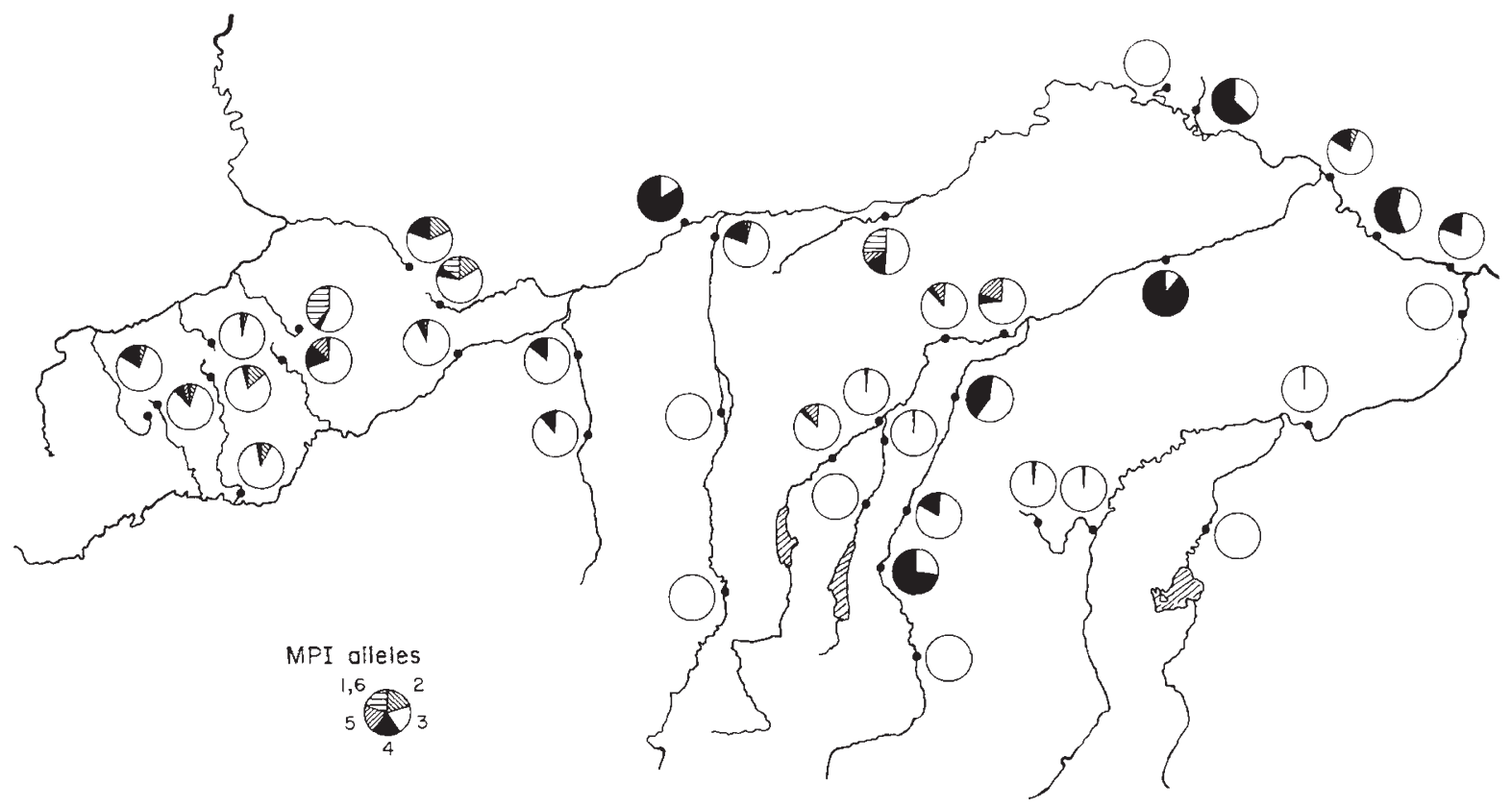

Fig. 3 Allele frequencies at the Mpi locus.

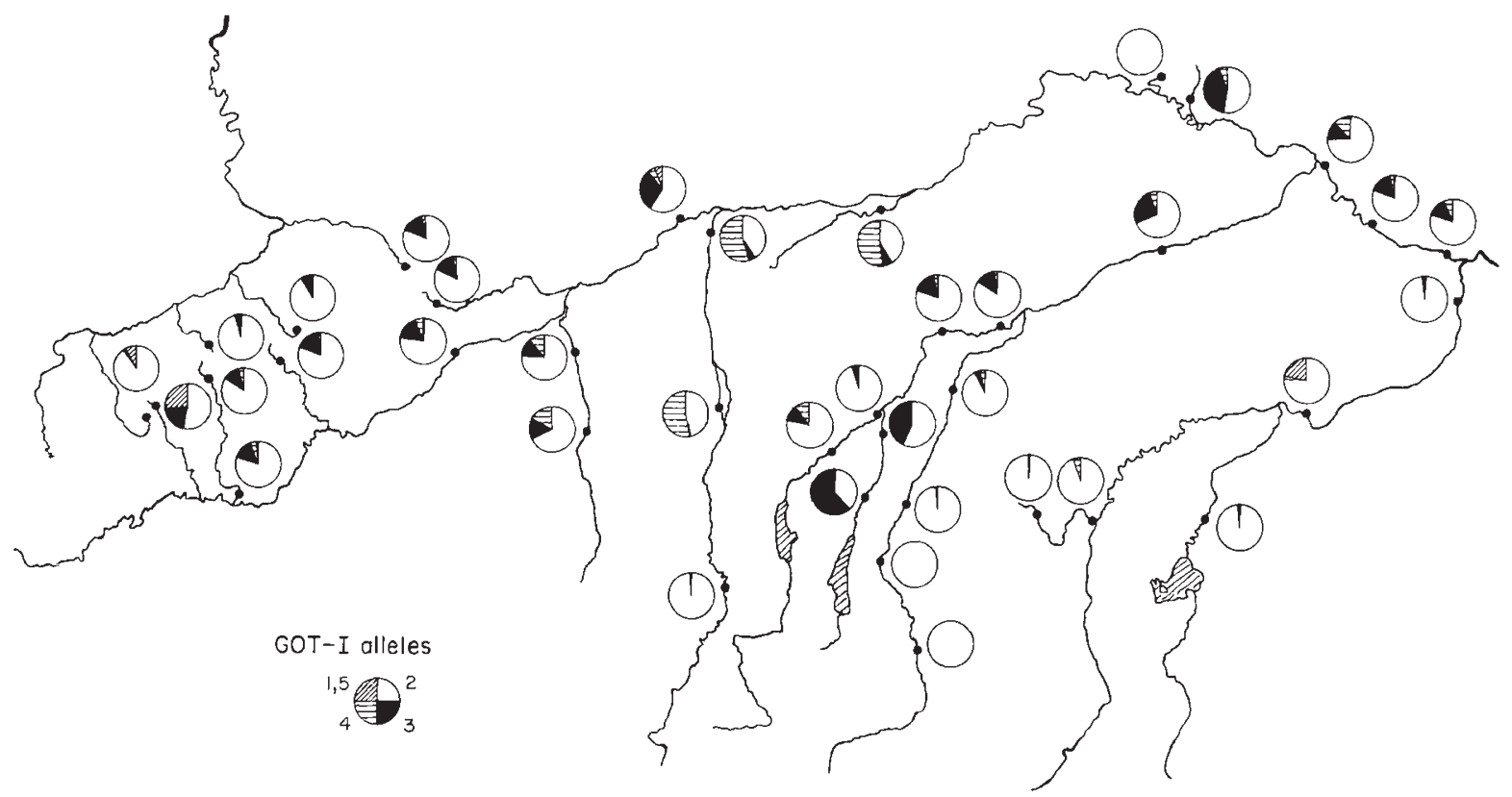

Fig. 4 Allele frequencies at the Got I locus.

tests for homogeneity of the allele counts. Alleles were pooled so that the expected numbers always exceeded one. No tests were carried out when this criterion was not met. The test statistics for the single loci are summed and can be used for an overall test. Nine of the 10 comparisons are significant at the 5 per cent level, most of them even at the 0.1 per cent level. A single pair of neighbouring populations does not differ significantly (Ink/Sch). The reason is probably the small size (44) of the sample from Ink. The collected samples can therefore be considered to stem from different populations that are partially isolated from each other. 


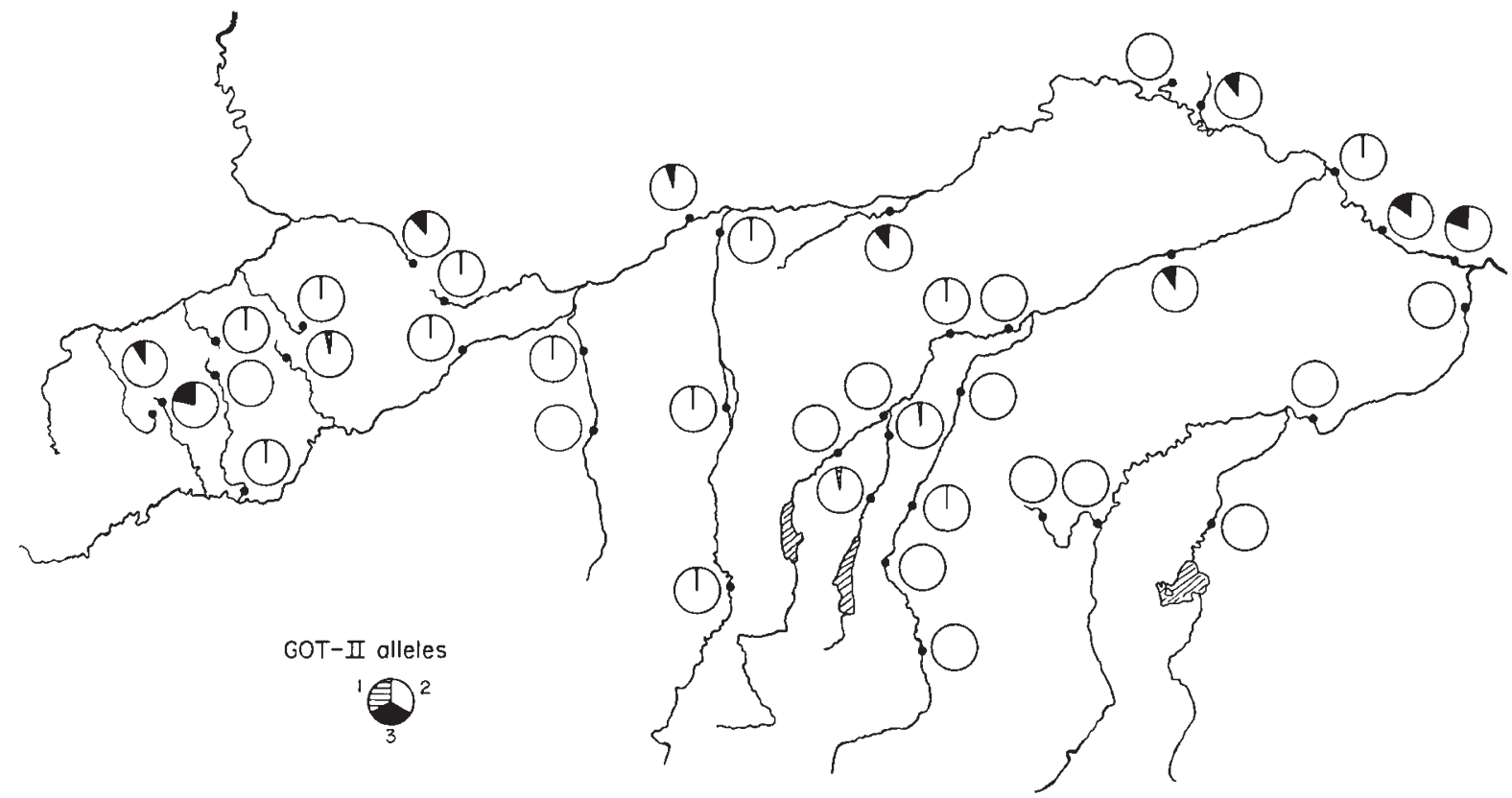

Fig. 5 Allele frequencies at the GotII locus.

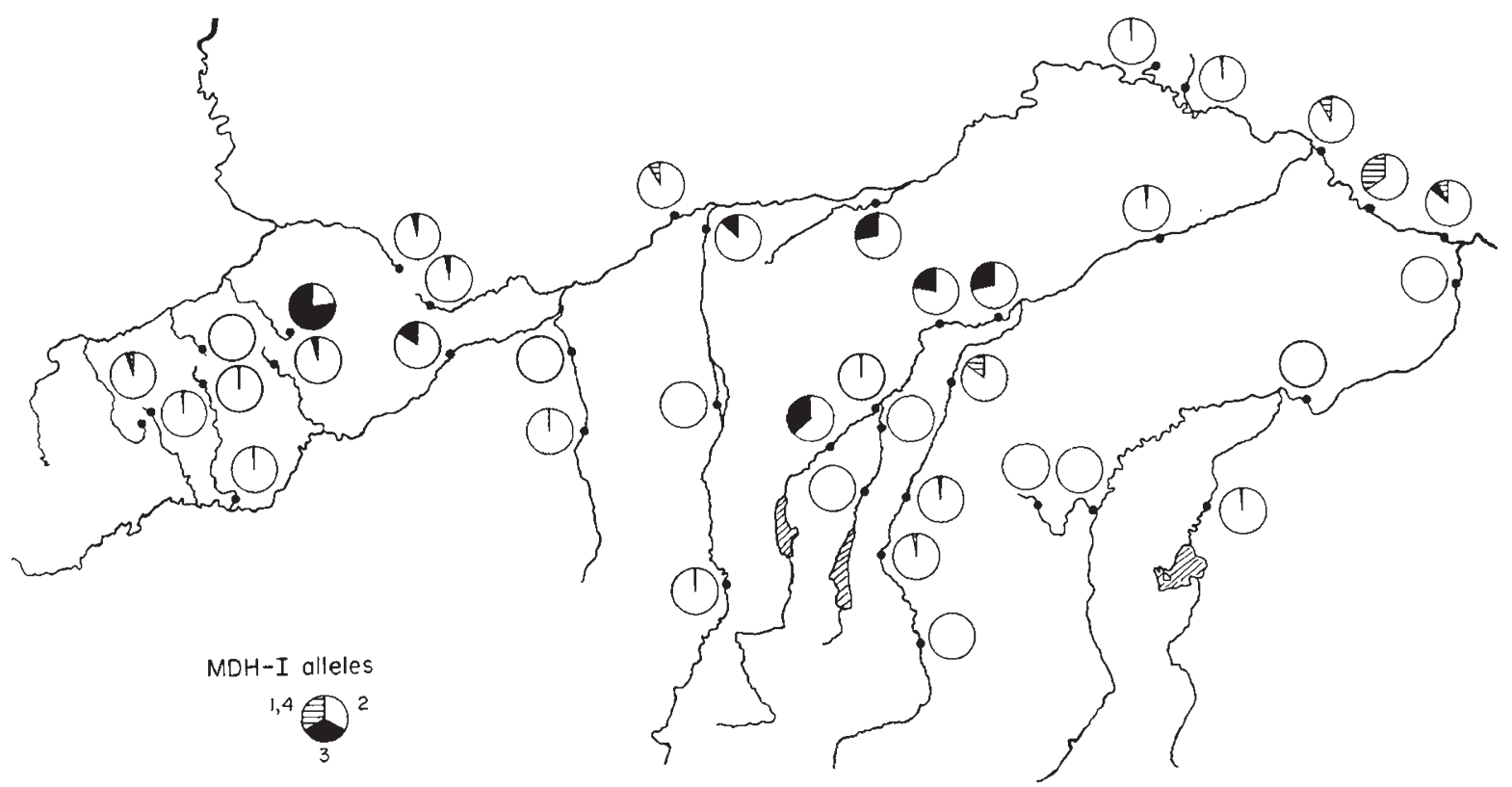

Fig. 6 Allele frequencies at the $M d h I$ locus.

All populations differ from each other, but the genetic differentiation is not homogeneous among the 38 populations. Neighbouring populations in small rivers differ less from each other. There are only four pairs of neighbouring populations (Lau-Ste, Bau-Bur, Kar-Sto, Att-Gra) in small rivers with a mean water flow of $10 \mathrm{~m} \mathrm{~s}^{-3}$ and less. The genetic distances of these four pairs are among the seven lowest of all neighbouring populations (Table 7). This may be explained by a higher migration rate in small rivers.

Four populations from the Rhine drainage system were included in the study in order to measure the 


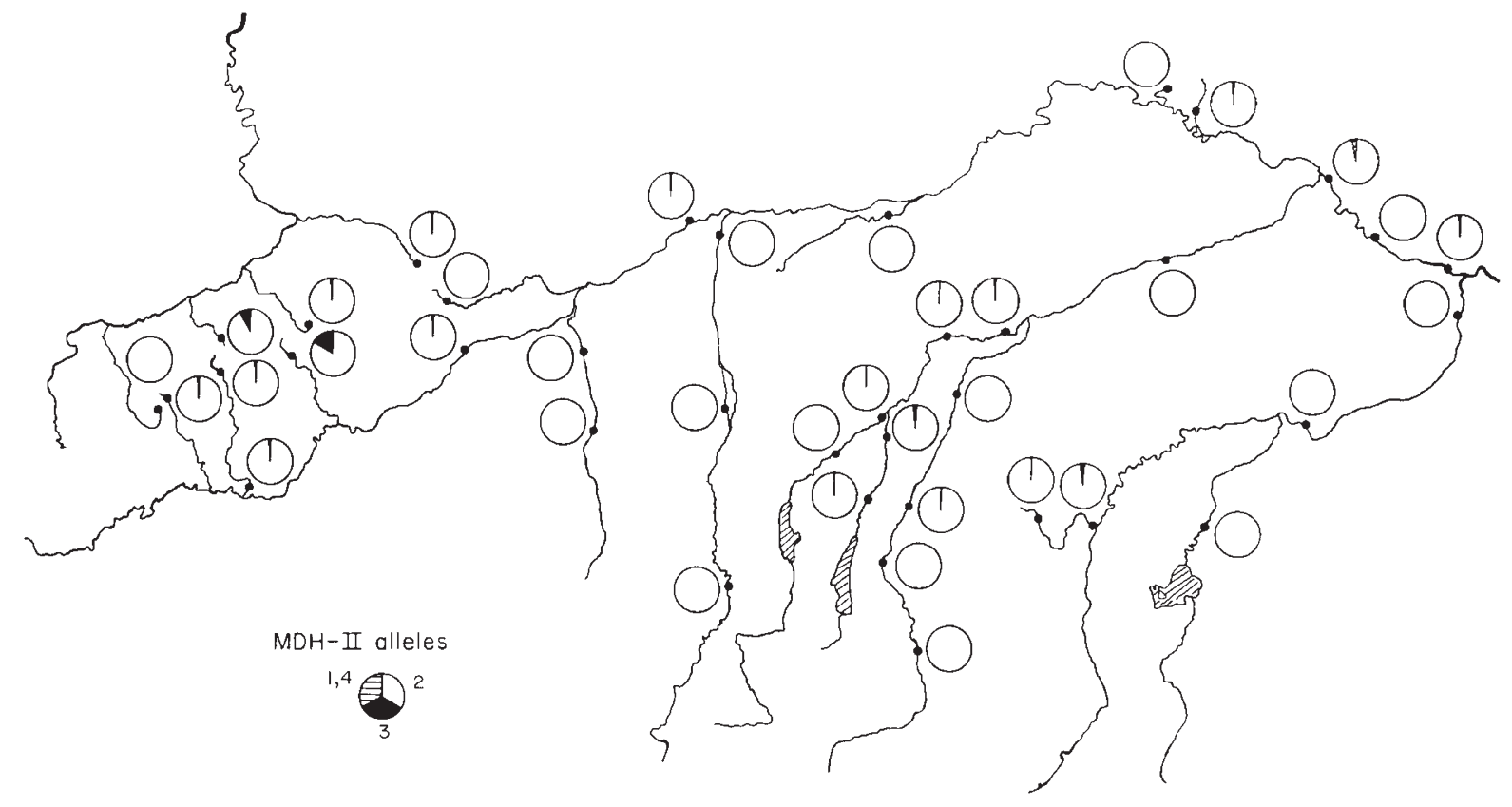

Fig. 7 Allele frequencies at the $M d h I I$ locus.

differentiation across a major watershed. In one of these, Ams, a new allele, $G p i^{9}$, turned up; but the frequency of this allele was low. Thus, the watershed does not seem to function as a major gene flow barrier. Furthermore, the average genetic distance of the four pairs of populations separated by the watershed $(\bar{D}=0.135$; range $0.01-0.4)$ does not differ significantly from the average genetic distance of all the other neighbouring population pairs separated by larger rivers $(\bar{D}=0.105$; range $0.01-0.3) \quad(t$-test: $P>0.5)$. The watershed among the Rhine and Danube drainage basins is a migration barrier comparable to uninhabitable larger rivers within the Danube drainage basin. The reason is probably that this watershed is not very pronounced. The tributaries of the river Neckar have eaten into the area of the former Danube system and thus the springs of the two drainage systems are now lying in the same old valley of the former Danube system and are very close together.

The whole population of $G$. fossarum from the Danube and the Rhine drainage basins is not panmictic. G. fossarum is subdivided in a number of local populations. The degree of differentiation varies among the six loci (see Figs 2-7) and can be summarized by Wright's $F$-statistics, $F_{\text {IT }}, F_{\text {IS }}$ and $F_{\text {ST }}$ (Wright, 1951). $F_{\mathrm{IT}}$ is the correlation of genes within individuals relative to the total population. $F_{\text {IS }}$ is a similar correlation within subpopulations; it is a measure of the deviation from Hardy-Weinberg proportions. $F_{\mathrm{ST}}$ is a measure of the genetic differentiation among sub-populations. The values for the single loci and an estimate using all six loci are given in Table 8. As expected, the single locus values of $F_{\text {IS }}$ are not significantly different from zero (the absolute values of the estimates differ less than 1.96 times the standard deviation from zero). This is simply another way to test for Hardy-Weinberg expectations, which already have been accepted using conventional one-locus tests and tests for random union of gametes in the two-locus combinations. But all six values are positive and the estimate of $F_{\text {IS }}$ using all six loci differs significantly from zero which suggests a slight excess of homozygotes in the populations.

With these low $F_{\text {IS }}$ values, the $F_{\text {IT }}$ do not differ much from the $F_{\mathrm{ST}}$-values. Of these all but one, the value for $M d h I I$, differ significantly from zero. The largest differentiation among the populations is observed at the Gpi locus followed by the loci Mpi, MdhI, GotI, GotII and MdhII.

The populations of $G$. fossarum are highly differentiated which indicates a limited genetic exchange among the populations. Gammarids are lined up in a single dimension in individual rivers and are connected to the populations in other rivers at the branches of the rivers. Therefore, a one- or two-dimensional stepping stone model does probably fit better than the island model, which assumes a symmetric migration among all populations. Slatkin \& Barton (1989) have shown 
Table 7 Comparison of neighbouring populations with small genetic distances

\begin{tabular}{|c|c|c|c|c|c|c|c|c|c|c|}
\hline $\begin{array}{l}\text { Population } \\
\text { pair }\end{array}$ & $\begin{array}{l}\text { Lau } \\
\text { Ste }\end{array}$ & $\begin{array}{l}\text { Att } \\
\text { Gra }\end{array}$ & $\begin{array}{l}\text { Bur } \\
\text { Bau }\end{array}$ & $\begin{array}{l}\text { Ink } \\
\text { Sch }\end{array}$ & $\begin{array}{l}\text { Tue } \\
\text { Alt }\end{array}$ & $\begin{array}{l}\text { Tue } \\
\text { Vor }\end{array}$ & $\begin{array}{l}\text { Kar } \\
\text { Sto }\end{array}$ & $\begin{array}{l}\text { Tue } \\
\text { Att }\end{array}$ & $\begin{array}{l}\text { Min } \\
\text { Gro }\end{array}$ & $\begin{array}{l}\text { Bau } \\
\text { Ulm }\end{array}$ \\
\hline $\begin{array}{l}\text { Genetic distance } \\
\quad G p i\end{array}$ & 0.0023 & 0.0028 & 0.0029 & 0.0056 & 0.0073 & 0.0073 & 0.0084 & 0.0141 & 0.0147 & 0.0296 \\
\hline$\chi^{2}$ & 30.96 & 7.44 & 9.66 & 2.36 & & & 0.372 & 31.73 & 6.33 & 116.17 \\
\hline d.f. & 3 & 2 & 3 & 2 & & & 2 & 1 & 1 & 5 \\
\hline$P$ & 0.000 & 0.024 & 0.022 & 0.307 & & & 0.830 & 0.000 & 0.012 & 0.000 \\
\hline \multicolumn{11}{|l|}{$M p i$} \\
\hline$\chi^{2}$ & 3.86 & 5.73 & 0.66 & 8.01 & & & & 0.40 & 13.18 & 9.54 \\
\hline d.f. & 3 & 2 & 2 & 2 & & & & 1 & 1 & 2 \\
\hline \multirow{2}{*}{\multicolumn{11}{|c|}{ GotI }} \\
\hline & & & & & & & & & & \\
\hline$\chi^{2}$ & 4.28 & 8.69 & 4.44 & 0.55 & 42.42 & 9.91 & 16.47 & 41.01 & 4.25 & 3.19 \\
\hline d.f. & 3 & 1 & 2 & 2 & 2 & 1 & 1 & 2 & 1 & 2 \\
\hline$P$ & 0.233 & 0.003 & 0.108 & 0.758 & 0.000 & 0.002 & 0.000 & 0.00 & 0.039 & 0.203 \\
\hline \multicolumn{11}{|l|}{ GotII } \\
\hline$\chi^{2}$ & & & & 2.89 & & & 0.74 & & & 0.38 \\
\hline d.f. & & & & 1 & & & 1 & & & 1 \\
\hline$P$ & & & & 0.089 & & & 0.389 & & & 0.54 \\
\hline \multicolumn{11}{|l|}{$M d h I$} \\
\hline$\chi^{2}$ & 0.58 & & & 1.26 & & & & & 15.25 & 43.03 \\
\hline d.f. & 1 & & & 1 & & & & & 1 & 1 \\
\hline$P$ & 0.448 & & & 0.261 & & & & & 0.000 & 0.00 \\
\hline \multicolumn{11}{|l|}{ MdhII } \\
\hline$\chi^{2}$ & 0.12 & 3.58 & & & & & 1.57 & 4.06 & & 4.49 \\
\hline d.f. & 1 & 1 & & & & & 1 & 1 & & 1 \\
\hline$P$ & 0.725 & 0.058 & & & & & 0.210 & 0.044 & & 0.034 \\
\hline \multicolumn{11}{|l|}{ Sum } \\
\hline$\chi^{2}$ & 39.79 & 25.43 & 14.76 & 15.08 & 42.42 & 9.91 & 19.16 & 73.14 & 39.02 & 176.79 \\
\hline d.f. & 11 & 6 & 7 & 8 & 2 & 1 & 5 & 5 & 4 & 12 \\
\hline$P$ & 0.000 & 0.000 & 0.039 & 0.058 & 0.000 & 0.002 & 0.002 & 0.000 & 0.000 & 0.000 \\
\hline
\end{tabular}

Table $8 F$-statistics

\begin{tabular}{llllllll}
\hline Locus & $\hat{F}_{\text {IT }}$ & s.d. $\left(\hat{F}_{\text {IT }}\right)$ & $\hat{F}_{\text {IS }}$ & s.d. $\left(\hat{F}_{\text {IS }}\right)$ & $\hat{F}_{\text {ST }}$ & s.d. $\left(\hat{F}_{\mathrm{ST}}\right)$ & $N$ \\
\hline Gpi & 0.541 & 0.059 & 0.016 & 0.016 & 0.534 & 0.058 & 37 \\
Mpi & 0.354 & 0.071 & 0.024 & 0.025 & 0.342 & 0.071 & 38 \\
GotI & 0.235 & 0.046 & 0.018 & 0.020 & 0.224 & 0.041 & 38 \\
GotII & 0.134 & 0.030 & 0.048 & 0.025 & 0.092 & 0.017 & 38 \\
MdhI & 0.313 & 0.137 & 0.015 & 0.031 & 0.303 & 0.146 & 38 \\
MdhII & 0.109 & 0.081 & 0.048 & 0.043 & 0.064 & 0.041 & 38 \\
All loci & 0.389 & 0.039 & 0.021 & 0.009 & 0.375 & 0.041 & 38 \\
\hline
\end{tabular}

that $F_{\mathrm{ST}}$ provides a good estimate of $\mathrm{Nm}$ under a variety of migration models, so that the assumption of either an island model or a stepping stone model is not important. Based on the $F_{\mathrm{ST}}$ estimate over all loci (Table 8) the number of migrants exchanged per generation is found as $N m=0.42$. This is an estimation of the average gene flow among all populations. It is possible that local populations are quite isolated (like the populations Len, Apf, Doe and Ulm) or that there are populations with higher gene flow than the 
estimated one (e.g. between Bau and Bur). Furthermore, the gene flow parameter $\mathrm{Nm}$ does not necessarily indicate a current gene exchange but can also reflect historical events. This will be discussed later. The gene flow estimate only equals the actual gene exchange if the populations are at a genetic equilibrium, e.g. an equilibrium with mutation, genetic drift and migration. The smaller the actual gene flow, the longer it takes until the equilibrium is reached.

The geographical position of the populations in the river system should reflect the genetic structure because migration mainly occurs along the rivers. Therefore, a tree which shows the genetic relationship should roughly correspond to the tree that consists of the branching rivers.

We have chosen the program CONTML (Felsenstein, 1981) to estimate the genetic relationship among the populations. This procedure assumes that the populations branch and evolve independently by random genetic drift. With a suitable choice of parameters, migration and drift can produce a similar population structure (Felsenstein, 1982). It is not possible to determine what are the main evolutionary forces that determine the population structure but we feel that Felsenstein's method is well suited to describe the genetic relationship among populations within species.

Figure 8 shows the tree of the genetic relationship of 37 populations (population Wie was dropped, because the locus Gpi was unscorable). This tree does not exactly reflect the geographical arrangement of the populations but the correspondence is good. For example, all populations of the river Inn (Alt, Att, Gra, Tue, Vor) are clustered. The two Würm populations (Kar, Sto) are on a branch that is connected with three of the Amper populations (Ffb, Ink, Sch). The latter branch is close to other populations of the Isar (Gro, Hor, Loi, Min) and populations of the lower part of the Danube (Don, Hil, Koe, See). Furthermore, one can see the closely related population pairs, both neighbouring pairs (Bau-Bur, Sto-Kar, Lau-Ste, Gra-Att) as well as the pair fixed for the same alleles by conincidence (Len-Wel). Most of the populations of the upper part

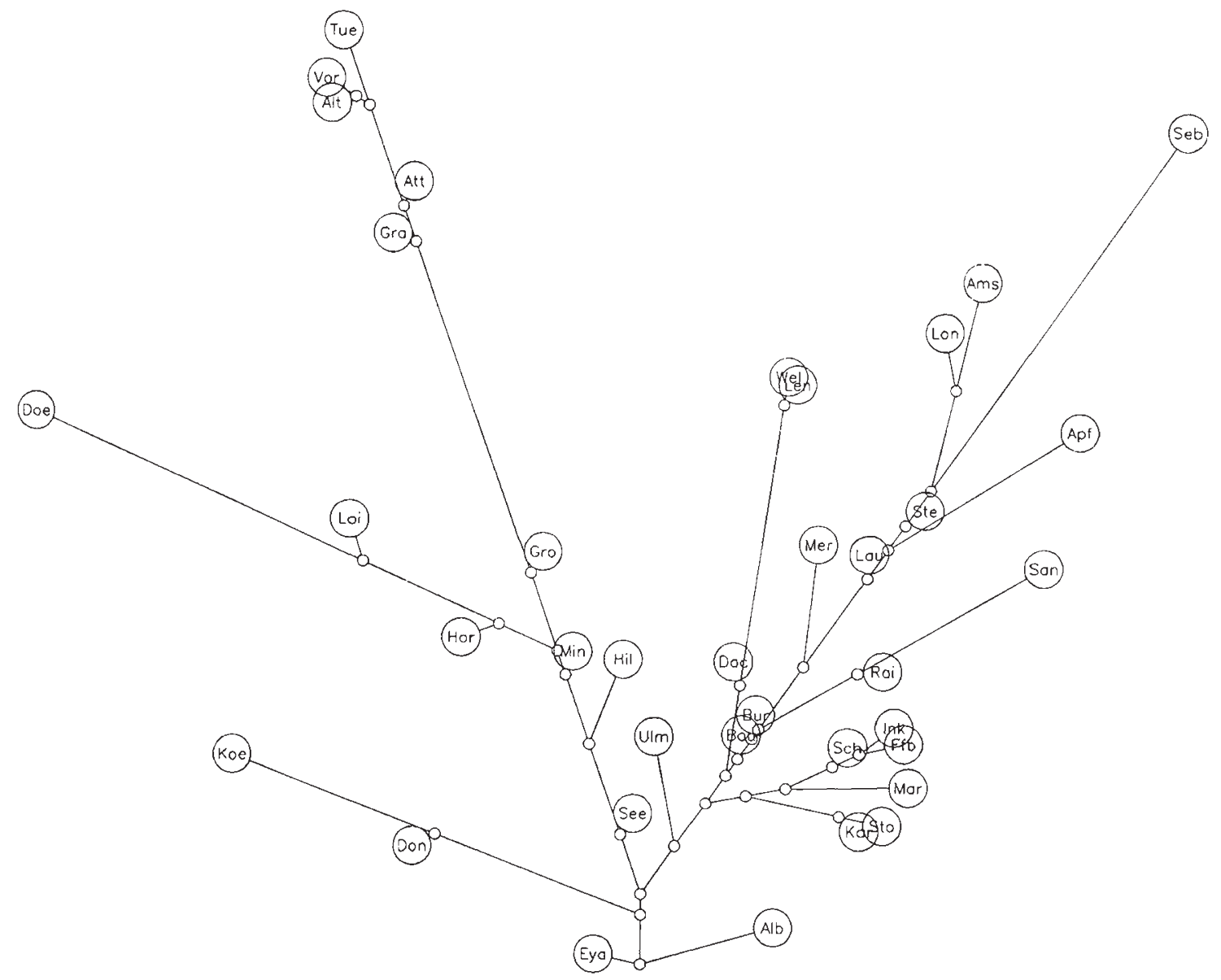

Fig. 8 Tree to describe the genetic relationship among the populations (Wie excluded, see text). 
of the Danube system (Apf, Bau, Bur, Lau, Lon, Mer, Rai, San, Ste) are grouped at the upper part of the tree, except some genetically isolated populations (Alb, Mar, Ulm). It is interesting that two population pairs, separated by the main watershed between the Rhine and Danube, are genetically close (Ams-Lon, Alb-Eya) and one is genetically distant (Mar-Seb).

The program conTML has an option to compare trees with different topologies. It is possible, therefore, to test whether a phylogenetic tree estimated under the constraint that its topology is identical to the geographical positions of the populations is different from the maximum likelihood tree. The geographical positions can be described with a bifurcating tree. The populations from the Rhine drainage system are included in a way such that each population is situated on a branch connected to its closest neighbour in the Danube system. The likelihood of the 'geographical' tree is 1.9 times its standard deviation lower than the maximum likelihood tree. Thus, we conclude that the 'geographical' tree does not differ significantly at the 5 per cent level from the phylogenetic tree.

\section{Discussion}

\section{Linkage disequilibrium}

We have described and analysed the population structure with the single locus allele frequencies, thereby treating the alleles at the different loci as independent. The tests for linkage disequilibrium suggested that at the combinations of the loci Mpi, GotI and GotII, the linkage disequilibrium parameter differed significantly from zero in several populations (Tables 4-6). The cause for these deviations might be selection at the loci involved (or at some linked loci), random genetic drift, inbreeding or gene flow (Hedrick et al., 1978). From the data it is not possible to determine which is the main cause.

Natural selection seems unlikely to us. There are few reported examples of natural selection on isozyme loci (Endler, 1986) and selection coefficients would have to be high for selection to be effective in the populations that sometimes undergo bottlenecks. Inbreeding does not seem likely, either because there were no indications of deviations from Hardy-Weinberg proportions. Gene flow also seems unlikely as a cause. Figures 2-7 reveal that it is difficult to produce the observed linkage disequilibria by gene flow from neighbouring populations. A common impression is that the populations with linkage disequilibrium either have about the same gene frequency at one of the loci as neighbouring populations, which cannot produce linkage disequilibrium through mixing, or have gene frequencies that cannot be produced through a mixture of neighbouring populations. (It is, of course, always possible to postulate that there are neighbouring populations with allele frequencies suitable to produce the observed linkage disequilibria through population admixture and that the populations have been sampled in a manner that was too coarse grained.)

The most probable cause for the observed linkage disequilibria is random genetic drift and bottlenecks that occur at periods with unfavourable conditions, e.g. drought or flood. In addition, periods with excessive pollution, often combined with a high parasite infestation of acanthocephalan larvae, can contribute to reductions in the population size with increased genetic drift.

Only three loci were involved in the combinations of linkage disequilibria that were significant when summed over the populations. The reason for this could be that the three loci are linked and, therefore, that the linkage disequilibria decrease more slowly than among loci on different chromosomes (Gammarids have $n \approx 26$, Orian \& Callan, 1957). This is only a guess. Unfortunately, there is almost no information about linkage maps in gammarids. We only know a single study where linkage has been studied between two loci: the Mpi and Gpi loci in the marine Gammarus oceanicus segregate independently (Siegismund, 1985b).

\section{Population structure}

The $G$. fossarum populations have been sampled over a period of 4 years. Therefore, temporal changes could have contributed to an increased value of the $F_{\mathrm{ST}}$ estimate. The contribution is probably small as most samples from particular rivers were sampled over a relatively short period and, except for one case, all pairs of neighbouring populations had genotype distributions that differed significantly from each other.

The local populations of $G$. fossarum show a strong genetic differentiation compared to the populations of G. roeseli (Siegismund, 1988), G. pulex (Scheepmaker \& van Dalfsen, 1989) and most marine gammarids (Bulnheim \& Scholl, 1981, 1982; Siegismund, 1985a; Siegismund et al., 1985). This is indicated by a high $F_{\mathrm{ST}}$-value. The reason is probably that the distribution of $G$. fossarum is restricted to the upper reaches of rivers. Therefore, the population of different rivers are quite isolated. An even higher geographical differentiation is found in G. minus, a resident of caves and springs (Gooch \& Hetrick, 1979). Generally, a positive correlation is found between the level of habitat isolation and the degree of genetic differentiation. The same pattern was found for amphipods living in the marine environment. Species restricted to low salinities are 
spatially isolated and thus show an increased genetic differentiation among their populations than species at higher salinities (Bunheim, 1985; Bulnheim \& Scholl, 1981, 1982; Siegismund, 1985a; Siegismund et al., 1985).

In a study of the large-scale differentiation of $G$. fossarum populations from Belgium, Switzerland, Germany and France, Scheepmaker \& van Dalfsen (1989) included three populations of the species $G$. fossarum from the Danube drainage system near Regensburg. Their average genetic identity among the Regensburg populations $(I=0.97$; range $0.96-0.98)$ is similar to that in the present study for neighbouring populations $(I=0.91$; range $0.74-1)$. The genetic identities between the Regensburg populations and the other European populations $(I=0.69$; range $0.63-0.79$ ) were smaller. This is remarkable, because they studied 20 loci, 14 more than we did. Generally the genetic identity increases when more loci are included. The last mentioned value of genetic identity was even lower than the value that they found between the species G. fossarum and G. pulex. Scheepmaker \& van Dalfsen (1989) proposed the term $G$. fossarum sensu stricto for the populations from the surroundings of its former type locality in Regensburg in order to separate them from $G$. fossarum sensu lato from other parts of Europe (France, Belgium, Switzerland, Netherlands). Regensburg is located in the Danube drainage system near population Wel (Fig. 1), thus we are dealing with $G$. fossarum sensu stricto.

It seems that the border to G. fossarum sensu lato is outside our study area because we did not find a pronounced change in the genetic structure between the populations of the Danube system and the four populations of the Rhine system. It might be possible, therefore, that races of $G$. fossarum are separated by wide lowlands, where this species is rare.

Gene flow is probably higher in small than in large rivers. We estimated an average gene flow $N m=0.42$, a value that in Wright's island model indicates a large differentiation among local populations. Scheepmaker (1990) calculated a higher $N m$-value $(N m=0.99)$ for three populations from the Regensburg area. On a larger scale, including samples of $G$. fossarum sensu lato populations from several contries in Western Europe, Scheepmaker (1990) found $\mathrm{Nm}$ values that on average were slightly lower than ours but reached the same conclusion, i.e. a substantial local differentiation.

Although, the population structure of $G$. fossarum can be described as discontinuous with the main discontinuities at migration barriers. Possible migration barriers are dams, reservoirs, channels, polluted waters, non-inhabitable big rivers (like the Danube and the lower reaches of the rivers Lech, Isar and Inn) and watersheds.

There are attributes of $G$. fossarum that fit to the above-mentioned suggestions. For example, $G$. fossarum does not have a free-swimming larval stage that can be easily swept downstream through unfavourable habitats. In fact, most of the migrating individuals in $G$. fossarum are adults that migrate actively (Goedmakers \& Pinkster, 1981). Therefore they tend to stay in their favourable habitat, which is a small river with high water current (relatively to the preferred habitat of $G$. roeseli and $G$. pulex) and low temperature. Furthermore, $G$. fossarum is sensitive to oxygen deficiency, acidity and pollution (Meijering \& Pieper, 1982).

In species with a high genetic differentiation among their local populations, discontinuous population structures are quite common. Gooch \& Hetrick (1979) found a similar structure for $G$. minus with discontinuities by watersheds and major rivers. Another example is the high genetic differentiation among populations of the marine copepod Tigriopus californicus (Burton \& Feldman, 1981). The high divergence occurred only between populations occupying different rock outcrops at a rocky shore, whereas populations sampled from the same outcrop were almost identical.

One possible explanation of the genetic pattern in $G$. fossarum populations is that there is a dynamic balance between genetic drift and gene flow. The divergence among the populations might be caused by rare migrational events and genetic drift. The populations are exposed to genetic drift by fluctuations of their population sizes or in extreme situations by local extinction and recolonization (founder effect). Normally, the population sizes of $G$. fossarum are high, but regular or irregular catastrophes might reduce the population sizes to the extent that genetic drift becomes very effective.

Most of the observed genetic differentiation pattern agrees with the suggested model of genetic drift and restricted gene flow. The populations of the Inn drainage system seem to be too homogeneous. Among these populations there are strong migration barriers such as dams, reservoirs and the major noninhabitable river Inn, so that a high gene flow cannot explain the situation. It seems more plausible that the Inn populations derived from a common founder population. This initial population might have been fixed at most of the studied loci through a founder effect. The Inn drainage system is the most polluted part of the studied area but recently the quality of the water has ameliorated (Anonymous, 1984, 1986). It 
might be possible that most of the Inn populations became extinct by pollution and recolonized recently. Larson et al. (1984) described a similar situation without the allelic fixation for the salamander Plethodon cinereus. The populations of a large formerly glaciated area showed a lower genetic differentiation than in populations inhabiting a smaller formerly nonglaciated territory. They argued that the populations of the glaciated part radiated after the glaciation from a single founder population, whereas the populations of the non-glaciated part existed in isolation in the long run. It should be mentioned that each genetic structure of existing populations is as a result of historical events (Avise \& Felley, 1979), but in most cases the historical development of the populations is unknown.

\section{Acknowledgements}

We are grateful to Francis Foeckler, Sabine Gießler, Angelika Küppers and Traudl McLaughlin for help in the collection of samples; to Angelika Küppers and Christine Steiger for technical help, to Dr J. Felsenstein for a copy of the program package PHYLIP and to Jürgen Jacobs, Maarten Scheepmaker and an anonymous reviewer for comments on the manuscript. HRS was supported by the German Science Foundation (DFG), grant no. Si 361/1-1 and by a grant from the Danish Natural Science Research Council.

\section{References}

ANONYMOUS 1984. Gewässergütekarten von Bayern. Bayerisches Landesamt für Wasserwirtschaft, Munich.

ANONYMOUS 1986. Gewässergütekarten von Bayern. Bayerisches Landesamt für Wasserwirtschaft, Munich.

AVISE, J. C. AND FELLEY, J. 1979. Population structure of freshwater fishes I. Genetic variation of Bluegill Lepomis macrochirus populations in man-made reservoirs. Evolution, 33, 15-26.

BRown, A. H. D. 1970. The estimation of Wright's fixation index from genotypic frequencies. Genetica, 41, 399-406.

BULNHEIM, H.-P. 1985. Genetic differentiation between natural populations of Gammarus tigrinus (Crustacea, Amphipoda) with reference to its range extension in European continental waters. Arch. Hydrobiol., 102, 273-290.

BULNHEIM, H.-P. AND SCHOLL, A. 1981. Genetic variation between geographic populations of the amphipods Gammarus zaddachi and G. salinus. Mar. Biol., 64, 105-115.

BULNHEIM, H.-P. AND SCHOLL, A. 1982. Polymorphism of mannose phosphate isomerase in North Sea and Baltic Sea populations of the amphipods Gammarus zaddachi and G. salinus. Mar. Biol., 71, 163-166.

BURTON, R. S. AND FELDMAN, M. w. 1981. Population genetics of Tigriopus californicus. II. Differentiation among neighboring populations. Evolution, 35, 1192-1205.
CHRISTENSEN, B., LOMHOLT, B. AND JELNES, J. J. 1974. Selection and mechanical mixing operating on a 2-allele amylase system in Asellus aquaticus (Isopoda, Crustacea). Hereditas, 77, 255-262.

CLAYTON, J. W. AND TRETIAK, D, N 1972. Amine-citrate buffers for $\mathrm{pH}$ control in starch gel electrophoresis. J. Fish. Res. Bd. Canada, 29, 1169-1172.

Endler, J. A. 1986. Natural Selection in the Wild. Princeton University Press, Princeton.

FELSENSTEIN, J. 1981. Evolutionary trees from gene frequencies and quantitative characters: finding maximum likelihood estimates. Evolution, 35, 1229-1242.

FELSENSTEIN, J. 1982. How can we infer geography and history from gene frequencies? J. Theor. Biol., 96, 9-20.

FELSENSTEIN, J. 1985. Confidence limits on phylogenies: an approach using the bootstrap. Evolution, 39, 783-791.

FRYDENBERG, O. AND SIMONSEN, v. 1976. Genetics of Zoarces populations V. Amount of protein polymorphism and degree of genic heterozygosity. Hereditas, 75, 221-232.

Goedmakers, A. AND PINKSTER, s. 1981. Population dynamics of three gammarid species (Crustacea, Amphipoda) in a French chalk stream, 3. Migration. Bijdr. Dierk., 51, 145-180.

GOOCH, J. L. AND HETRICK, S. w. 1979. The relation of genetic structure to environmental structure: Gammarus minus in a Karst area. Evolution, 33, 192-206.

HARRIS, H. AND HOPKINSON, D. A. 1976. Handbook of Enzyme Electrophoresis in Human Genetics. North-Holland Publishing Company, Amsterdam.

HEDRICK, P., JAIN, S. AND HOLDEN, L. 1978. Multilocus systems in evolution. Evol. Biol., 11, 101-184.

HILL, W. G. 1974. Estimation of linkage disequilibrium in randomly mating populations. Heredity, 33, 229-239.

KARAMAN, G. S. AND PINKSTER, S. 1977. Freshwater Gammarus species from Europe, North Africa and adjacent regions of Asia (Crustacea-Amphipoda). Part I. Gammarus pulexgroup and related species. Bijdr. Dierk, 47, 1-97.

LARSON, A., WAKE, D. B. AND YANEV, K. P. 1984. Measuring gene flow among populations having high levels of genetic fragmentation. Genetics, 106, 293-308.

MEIJERING, M. P. D. AND PIEPER, H. G. 1982. Die Indikatorbedeutung der Gattung Gammarus in Fließgewässern. Decheniana-Beihefte (Bonn), 26, 111-113.

NEI, M. 1972. Genetic distances between populations. Am. Nat., 106, 283-292.

ORIAN, A. J. E. AND CALlaN, G. 1957. Chromosome numbers in Gammarids. J. Mar. Biol. Ass. U.K., 36, 129-142.

PÈTRE-STROOBANTS, G. 1980. Diagnose préliminaire de Gammarus caparti, une nouvelle espèce de Gammarus de Belgique (Crustacea, Amphipoda). Bull. Ann. Soc. r. Belge Ent., 116, 135.

SAS InSTITUTE INC. 1987. SAS Procedures Guide Release 6.03 Edition, Cary, NC: SAS Institute Inc.

SCHWARTZ, M. J., NisSElbaum, s. AND Bodansky, o. 1963. Procedure for staining zones of activity of glutamic oxaloacetic transaminase following electrophoresis with starch gels. Am. J. Clin. Pathol., 40, 103-106.

SCHEEPMAKER, M. 1987. Morphological and genetic differentiation of Gammarus stupendus Pinkster, 1983 in the Massif 
de la Sainte Baume, France. Bijdr. Dierk., 57, 1-18.

SCHEEPMAKER, M. 1990. Genetic differentiation and estimated levels of gene flow in members of the Gammarus pulexgroup (Crustacea, Amphipoda) in western Europe. Bijdr. Dierk., 60, 3-30.

SCHEEPMAKER M. AND VAN DALFSEN, J. 1989. Genetic differentiation in Gammarus fossarum Koch, 1835 and $G$. caparti Pètre-Stroobants, 1980 (Crustacea, Amphipoda) with reference to G. pulex pulex in North-West-Europe. Bijdr. Dierk., 59, 127-139.

SIEGISMUND. H. R. 1985a. Genetic studies of Gammarus II. Geographical variation at polymorphic enzyme loci in Gammarus salinus and Gammarus oceanicus. Hereditas, 102, 15-23.

SIEGISMUND, H. R. 1985b. Genetic studies of Gammarus III. Inheritance of electrophoretic variants of the enzymes mannose phosphate isomerase and glucose phosphate isomerase in Gammarus oceanicus. Hereditas, 102, 25-31.

SIEGISMUND, H. R. 1988. Genetic differentiation in populations of the freshwater amphipods Gammarus roeseli and Gammarus fossarum. Hereditas, 109, 269-276.
SIEGISMUND, H. R., SIMONSEN, v. AND KOLDING, S. 1985. Genetic studies of Gammarus I. Genetic differentiation of local populations. Hereditas, 102, 1-13.

SLATKIN, M. 1985. Rare alleles as indicators of gene flow. Evolution, 39, 53-65.

SLATKIN, M. AND BARTON, N. H. 1989. A comparison of three indirect methods for estimating average levels of gene flow. Evolution, 43, 1349-1368.

SOKAL, R. R. AND RoHLF, F. J. 1981. Biometry, 2nd edn, W. H. Freeman and Company, San Francisco.

WEIR, B. S. AND COCKERHAM, C. C. 1979. Estimation of linkage disequilibrium in randomly mating populations. Heredity, 42, 105-111.

WEIR, B. S. AND COCKERHAM, C. C. 1984. Estimating F-statistics for the analysis of population structure. Evolution, 38, 1358-1370.

Wright, s. 1951. The genetical structure of populations. Ann. Eugen., 15, 323-354.

YNDGÅRD, C. F. 1972. Genetically determined electrophoretic variants of phosphoglucose isomerase and 6-phosphogluconate dehydrogenase in Zoarces viviparus $\mathrm{L}$. Hereditas, 71, 151-154. 